\title{
Evaluation of Methotrexate Toxicity and its Relationship with ABCB1 Genetic Polymorphism in Pediatric with Acute Lymphoblastic Leukemia
}

\section{Borhan Moradveisi}

Cancer and Immunology Research Center, Research Institute for Health Development, Kurdistan University of Medical Sciences, Sanandaj, Iran

\section{Ebrahim Mohammadi}

Kurdistan Environmental Health Research Center, Kurdistan University of Medical Sciences, Sanandaj, Iran

\section{Ebrahim Ghaderi}

Department of Epidemiology and Biostatistics, Faculty of Medicine, Kurdistan University of Medical Sciences, Sanandaj, Iran

\section{Fatemeh Zamani}

Cellular and Molecular Research Center, Research Institute for Health Development, Kurdistan University of Medical Sciences, Sanandaj, Iran

Farima Zakaryaei ( $\sim$ farima0258@gmail.com )

Department of emergency medicine, Kurdistan University of Medical Sciences, Sanandaj, Iran

\section{Research article}

Keywords: Acute lymphoblastic Leukemia, Methotrexate, Drug complications, ABCB1 gene

Posted Date: December 7th, 2020

DOI: https://doi.org/10.21203/rs.3.rs-121087/v1

License: (c) (i) This work is licensed under a Creative Commons Attribution 4.0 International License. Read Full License

Version of Record: A version of this preprint was published at Iranian Journal of Pediatrics on December 20th, 2021. See the published version at https://doi.org/10.5812/ijp.115502. 


\section{Abstract}

Background: Acute lymphoblastic leukemia(ALL) is the most common type of hematologic malignancy in children. Based on COG protocol, one of the treatments for these children is methotrexate. Methotrexate has many complications in Pediatrics. Nowadays, the relationship between gene mutations and complications of each drug are discussed. This study aimed to evaluate the pharmacogenetics of methotrexate with emphasis on ABCB1 gene and its implications for the treatment of ALL children in Kurdistan province.

Methods: Blood samples were obtained from children with ALL, and then DNA extraction and polymerase chain reaction (PCR) were performed with approximately $300 \mu \mathrm{Mol} / \mu \mathrm{L}$ of each direct primer in the final volume of $50 \mu \mathrm{L}$. The PCR method was used to amplify the ABCB1 gene and the reaction products were identified by $0.5 \%$ agarose gel electrophoresis. The length of the PCR fragments was confirmed by observation by UV-Trans-illuminator. Moreover, blood and liver toxicity in all patients treated with methotrexate were measured by measuring leukocyte counts, platelets, neutrophil percentages, hemoglobin, alanine transaminase activity, and aspartate trans Aminase was evaluated.

Results: 81 children with ALL, 45 males (55.5\%) and 36 females with a mean age of $6.32+3.08(\mathrm{y} / 0)$ were evaluated in this study. ABCB1 $3435 \mathrm{C}->\mathrm{T}$ gene mutation frequency was $70.4 \%$ and the frequency of ABCB1 1199 G->A gene mutation was 4.9\%.Frequency of gastrointestinal toxicity, leukopenia, anemia, thrombocytopenia, hepatotoxicity, neutropenia and renal toxicity were higher in patients with heterozygous and homozygous ABCB1 $3435 \mathrm{C}->$ T mutant polymorphisms than in patients with normal polymorphism, but the frequency of toxicity in patients with heterozygous and homozygous ABCB1 1199 G->A mutant polymorphisms were lower than patients with normal homozygous polymorphism, but these difference were not statistically significant.

Conclusion: According to the results of our study, it can be concluded that methotrexate drug toxicity was higher in patients with ABCB1 $3435 \mathrm{C}->\mathrm{T}$ gene mutation, but there was no significant correlation because of the low sample size. Furthermore it can be concluded that ABCB1 $1199 \mathrm{G}->$ A gene mutation may have a protective effect against the side effects of methotrexate, therefore it is recommended this hypothesis be tested in future studies.

\section{Background}

About 240,000 new cases of acute leukemia are diagnosed in children each year (1). This leukemia is caused by the overgrowth of immature lymphoid cells in the bone marrow and peripheral blood (2). the most common signs in ALL children are hepatomegaly (64\%), splenomegaly (61\%), paleness (54\%), fever (53\%), and bruising (52\%) (3).

Most of the children with leukemia are currently being treated, but many have long-term complications, so early prevention measures are urgently needed $(4,5)$. 
Children with ALL are treated according to the COG protocol. Treatment with the COG protocol begins with an induction phase followed by stabilization and maintenance. Based on this protocol, patients receive weekly methotrexate (20 mg / m2), daily 6-mercaptopurine (75 mg / m2), and vincristine and prednisolone pulses or dexamethasone every 28 days until the end of the maintenance phase. Doses of 6-mercaptopurine and MTX are adjusted between 2000-3000 / $\mu$ l and ANC over $500 / \mu l$ to achieve WBC. Similarly, the doses of 6-MP and MTX are reduced by $25 \%$ each time the number of red blood cells is less than 2,000 per microliter during treatment (6).

The duration of treatment is often about three years. More than $80 \%$ of children can be cured with proper medication and timely treatment (7). The dose of methotrexate adjusts according to the patient's age. The dose of $8 \mathrm{mg}$ is used in one to 2 years old, $10 \mathrm{mg}$ in 2 to 3 years, $12 \mathrm{mg}$ in 3 to 9 years, and $15 \mathrm{mg}$ in over nine years-old children (8).

Methotrexate can cause many complications and toxicities in patients. Hematologic toxicity occurred in $2-4 \%$ of all treated cases, the most common hematologic complications of this drug are leukopenia, thrombocytopenia, and anemia with a prevalence of 1-10\%. Pancytopenia, agranulocytosis, and hematopoietic disorders occur in $0.1-1 \%$ cases. This drug can also cause hepatic complications. High doses of this drug can increase serum ALT levels 10 to 20 times within 12 to 48 hours, and low to moderate doses of methotrexate can increase serum ALT or AST levels in 15 to $50 \%$ of patients. Moreover, taking this drug at the same time as other drugs, such as leflunomide or azathioprine, can cause more liver problems. Studies have shown that folic acid's concomitant administration reduces the frequency of elevated serum enzymes (9-14). Therefore, patients treated with MTX should have regular liver function tests and $\mathrm{CBC}$ to recognize bone marrow suppression and prevent pancytopenia $(14,15)$.

The expression patterns of ABCB1 gene polymorphisms can affect MTX's pharmacokinetics, which significantly affects MTX activity and toxicity, and it is associated with an increased risk of ALL in Asians $(16,17)$.

The ABCB1 gene, which copies the MDR1 protein, contains 28 exons and is located on chromosome 7 (q21.12) (18). High levels of ABCB1 expression lead to a decrease in the intracellular concentration of drugs. ABCB1 activity also plays an essential role in drug efficacy and drug toxicity during treatment and affects gastrointestinal absorption and renal or hepatic excretion of drugs (19).

Mutations at the 3435 point of the ABCB1 gene can cause C to T mutate, which is Wobble. In addition, in the mutation at 1199 points of this gene, $G$ to A nucleotide mutate changes the amino acid SER 400 to ASN 400, and the mutation of 1236 points causes C to T nucleotide mutate, which is Wobble too (20). Studies have shown that single-nucleotide mutations (SNPs) in MDR1 can also affect the p-glycoprotein protein's function (21). Furthermore, silent SNPs should not be neglected and should be considered in medication programs (22).

Given that the toxicity of methotrexate is unavoidable even in some leukemia patients, despite standard methods and advanced clinical procedures, the toxicity of this drug and the recognition of the patient's 
genetic factors (mutant alleles) in the identification of patients at risk for hematologic and hepatic toxicity of these drugs seem to be essential. It also further justifies such research, given that methotrexate is very inexpensive and is essential for treating acute leukemia in children, and there is no alternative to it.

\section{Methods}

\section{Study design and period \& Study area:}

This cross-sectional study was performed on all children with acute lymphoblastic leukemia between the ages of 1-15 years who admitted to the Besat hospital of Sanandaj, Kurdistan province, from 2012 to 2019.

\section{Inclusion criteria:}

1- Children in whom the disease was diagnosed based on clinical signs and bone marrow aspiration samples by the Department of Pediatric Hematology and Oncology during the years 2012 to 2019.

2-All children diagnosed with acute lymphoblastic leukemia during this study were treated with methotrexate.

\section{Exclusion criteria:}

1- Patients who have died.

2- Patients who are not willing to cooperate and participate in the study.

3- Patients who do not come to control and continue treatment for any reason.

\section{Data collection:}

Permission was obtained from the patients to conduct the research. Blood sampling and other procedures are part of the treatment process. Genetic tests are not part of the treatment process provided by design.

\section{Blood sampling}

In the study, a sample of $4 \mathrm{cc}$ of peripheral blood was taken. Blood samples were collected in $\mathrm{CBC}$ tubes with EDTA anticoagulant and transferred to the laboratory at $4{ }^{\circ} \mathrm{C}$ and stored in the freezer.

\section{Diagnosis of disease and laboratory toxicity factors}

Blood toxicity and hepatotoxicity in all patients treated with methotrexate were monitored continuously, and the number of leukocytes, platelets, neutrophil percentage, hemoglobin, alanine transaminase activity, aspartate transaminase, was evaluated, Monitored, and recorded.

DNA sampling and extraction 
DNA was extracted from the samples stored in the freezer by using the Geneall kit. The quality and quantity of DNA extracted were determined by spectrophotometry and nanodrop device at 230, 260, and $280 \mathrm{~nm}$.

\section{Polymerase chain reaction}

PCR was performed using DNA from various tissues and organisms, including peripheral blood, skin, hair, saliva, and germs. Geneall Korea Kit extracted DNA. A small amount of DNA was required for PCR to produce sufficient copies to be analyzed using conventional laboratory methods.

\section{RFLP}

After amplifying the desired fragments of the ABCB1 gene by the PCR technique, the RFLP method, and cutting of fragments at mutation points were used to examine the variants of these genes, Mbo-I, and Acu-I enzymes used to cut the amplified fragments of C3435T, and G1199A of the ABCB1 gene, respectively.

Finally, the size of the amplified fragments was compared with DNA markers on the agarose gel. After exposing the PCR reaction product to the incubator's relevant enzymes for 12 hours, the reaction products were detected using $3 \%$ agarose gel electrophoresis. The length of PCR fragments was also confirmed by observation by V-Trans-illuminator(Fig. 1and2).

\section{Sequencing:}

Some samples of heterozygous and homozygous mutants were sequenced by the Sanger method to ensure the RFLP reaction's accuracy. At this stage, the PCR reaction for the sample repeated twice; the product was purified with a PCR purification kit and sent for sequencing.

\section{data analyzing:}

Collected information was entered into SPSS software. The incidence of each of the drug side effects calculated in different groups. In addition, the changes before and after each of the indicators were used for analysis. To compare quantitative variables between different groups, ANOVA and T-tests, and in the absence of normal distribution, Kruskal-Wallis and Mann-Whitney U tests were used. A Chi-square test was used to compare qualitative variables between different groups, and a paired t-test was used for before and after comparisons.

\section{Results}

This study performed on 81 children with ALL (45 boys (55.5\%) and 36 girls) with a mean age of $6.32+$ $3.08 \mathrm{y} / \mathrm{o}$. The frequency of ABCB 1 gene mutation at $3435 \mathrm{C}->\mathrm{T}$ was $70.4 \%$ and at $1199 \mathrm{G}->\mathrm{A}$ point was $4.9 \%$, on the other hand(Fig. 1and2), the frequency of gastrointestinal toxicity ( $p$-value $=0.619)$, leukopenia $(p$-value $=0.724)$, anemia $(p$-value $=0.121)$, thrombocytopenia $(p$-value $=0.116)$, 
hepatotoxicity $(p$-value $=0.096)$, neutropenia $(p$-value $=1.000)$ and renal toxicity $(p$-value $=1.000)$ in patients with heterozygous and homozygous polymorphisms ABCB 1 gene mutation at $3435 \mathrm{C}->\mathrm{T}$ was higher than patients with normal homozygous polymorphism. Therefore, according to the findings, it can be concluded that the rate of blood, gastrointestinal, hepatic, and renal toxicity of methotrexate in patients with $A B C B 1$ gene mutation is higher at $3435 \mathrm{C}->T$, but this difference cannot be statistically significant due to low volume. On the other hand, due to the high prevalence of $A B C B 1$ gene mutation at point 3435 in patients with ALL, this mutation may be a risk factor.

Frequency of gastrointestinal toxicity $(p$-value $=1.000)$, leukopenia $(p$-value $=1.000)$, anemia $(p$-value $=$ $0.597)$, thrombocytopenia ( $p$-value $=1.000)$, hepatotoxicity $(p$-value $=0.630)$, neutropenia $(p$-value $=$ $0.308)$ and renal toxicity $(p$-value $=1.000)$ in patients with heterozygous and homozygous polymorphisms of $A B C B 1$ gene mutation at $1199 \mathrm{G}->A$ point was lower than patients with normal homozygous polymorphisms, but this difference was not statistically significant. Therefore, it is possible that the ABCB1 gene mutation at $1199 \mathrm{G}->A$ could have a protective effect against methotrexate complications in individuals with this gene mutation.

\section{Discussion}

Acute Lymphoblastic Leukemia (ALL) is the most common type of hematologic malignancy in children. Although most children with leukemia are currently diagnosed and treated, many have long-term complications. The duration of treatment is about three years. More than $80 \%$ of children diagnosed with ALL recover completely. Methotrexate has been proven as a treatment in patients with ALL, but it can cause many complications. Therefore, it is precious to study the factors that cause or exacerbate these complications. Evaluation of this drug's toxicity and recognition of the patient's genetic factors (mutant alleles) in identifying patients exposed to the hematologic and hepatic toxicity of this drug is necessary.

In our study, the prevalence of ABCB 1 gene mutation at point $3435 \mathrm{C}->\mathrm{T}$ was $70.4 \%$ and the prevalence of $A B C B 1$ gene mutation at point $1199 \mathrm{G}->$ A was $4.9 \%$, while, the allelic frequency of Ser400Asn in the Caucasian population was $5.5 \%$ and the prevalence of $A B C B 1$ gene mutation at 3435 was reported to be 53.9. (23).

In CML patients, the prevalence of ABCB 1 gene mutation in 3435 points was $60 \%$ in the normal population and $87.14 \%$ in the $C M L$ population (24). Moreover, the prevalence of this mutation in the Japanese population was $72.7 \%$, and in Italy's Tuscany population was $69.6 \%$ (25).

The results of our study showed that the frequency of gastrointestinal toxicity, leukopenia, anemia, thrombocytopenia, hepatotoxicity, neutropenia, and nephrotoxicity in patients with heterozygous and homozygous mutant mutations of $A B C B 1$ gene at point 1199 is less than patients with polymorphism.

To date, no study has been done on the association of $A B C B 1$ gene polymorphisms at point 1199 with gastrointestinal, hematologic, hepatic, and kidney toxicity. However, studies on this gene mutation have shown that the risk of recurrence in patients with 1199GA polymorphisms increased 2.9 times compared 
to $1199 \mathrm{GG}$, suggesting that the $1199 \mathrm{G}->\mathrm{A}$ ABCB1 mutation may be a new predictor of prognosis in children (40). Woodahl et al. said that MDR1 G1199A polymorphism might play an anticancer role by modulating drug distribution and delivering tumor cells (26).

Data analysis results showed the frequency of gastrointestinal toxicity, leukopenia, anemia, thrombocytopenia, hepatotoxicity, neutropenia, and nephrotoxicity in patients with heterozygous and homozygous polymorphisms of $A B C B 1$ gene mutation is higher in patients with polymorphism at point 3435. However, this difference was not statistically significant. This result shows that the mutation of the $A B C B 1$ gene at $3435 \mathrm{C}->$ T point can increase the incidence of hematologic, hepatic, gastrointestinal, and renal toxicities. In addition, due to our results, high prevalence of $A B C B 1$ gene mutation at point 3435 in patients with ALL this mutation can be a risk factor for ALL.

A study of 127 Lebanese ALL patients by Zgheib et al. showed a statistically significant association between neutropenia (absolute neutrophil count < 500) and alkaline carriers of type ABCB1 rs 1045642 and $A B C B 1$ rs1128503. They also stated that genotyping for $A B C B 1$ polymorphism may be useful in identifying patients at risk for methotrexate toxicity (27).

The study of Gregers et al. showed that bone marrow toxicity in patients with TT genotype at 3435 points of the $A B C B 1$ gene during doxorubicin, vincristine, and Prednisolone therapy is more. Hepatotoxicity was also observed in high-dose treatment with methotrexate in patients with the $\mathrm{CC}$ genome at 3435 points (28). Another study showed that patients with different ABCB1 C3435T alleles showed a more significant reduction in neutrophils (for CC, CT, and TT, 63\%, 72\%, and $80 \%$ ) (29).

However, in a study by Yao et al., 78 single nucleotide polymorphisms (SNPs) in ABCB1, ABCC1, and ALDH1A1 were analyzed in 882 breast cancer patients. None of the SNPs in ABCB1 were associated with blood toxicity, and none of the 16 single nucleotide polymorphisms in ABCB1 or ALDH1A1 were associated with gastrointestinal toxicity (30).

On the other hand, the study of Samara et al. aimed to investigate the relationship between MDR1 C3435T and RFC1 G80A polymorphism with toxicity and response to methotrexate in rheumatoid arthritis patients, showing that there is a significant relationship between RFC1 G80A and MDR1 C3435T polymorphism with MTX toxicity. Patients with the RFC1 80GG genotype were at higher risk for gastrointestinal toxicity. Patients carrying at least one MDR1 3435T allele were at increased risk for MTX general toxicity, especially hepatotoxicity (31).

Suthandiram et al. illustrated that hepatic toxicity is associated with SLC19A1 G80A and ABCB1 C3435T and methotrexate plasma concentrations were significantly higher in patients with MTHFR C677T and ABCB1 C3435T polymorphisms (32).

In another study, Troels K Et al. examined the effect of paclitaxel in patients with ovarian cancer and the effect of genetic variants in CYP2C8 and $\mathrm{ABCB} 1$ on the toxicity and survival of the disease. They resulted 
that there was no statistically significant relationship between CYP2C8 and ABCB1. C1236T, G2677T / A, and C3435T with neutropenia, sensory neuropathy, and general survival (33).

\section{Conclusion}

Based on our study's findings, it can be concluded that the rate of drug toxicity of methotrexate is higher in patients with $A B C B 1$ gene mutation at point $3435 \mathrm{C}->T$, but due to the small sample size, no significant relationship was found. It is also suggested that the $A B C B 1$ gene mutation at $1199 \mathrm{G}->A$ could have a protective effect against the effects of methotrexate complications. Therefore, it is recommended that this hypothesis be tested in future studies. It is also recommended that further studies be performed on larger sample sizes.

\section{Abbreviations}

ALL: Acute lymphoblastic leukemia\

DNA; Deoxyribonucleic acid

ANC: absolute neutrophil count

6-MP :6- Mercaptopurine

MTX; methotrexate

ALT: Alanine aminotransferase

AST: aspartate aminotransferase

MDR1: Multi-Drug Resistance Gene

ABCB1: ATP Binding Cassette Subfamily B Member 1

CBC: complete blood count

EDTA: Ethylenediaminetetraacetic acid

RFLP: restriction fragment length polymorphism

CML: Chronic myelogenous leukemia

SNPs: Single nucleotide polymorphisms

ALDH1A1: Aldehyde dehydrogenase 1 family, member A1

SLC19A1: Solute Carrier Family 19 Member 1 
CYP2C8: Cytochrome P450 Family 2 Subfamily C Member 8

RFC1: Replication Factor C Subunit 1

MTHFR: Methylenetetrahydrofolate reductase

\section{Declarations}

\section{- Ethics approval and consent to participate}

Written consent was obtained from a parent or guardian for participants under 16 years old. This manuscript has been ethical approval by the ethics committee of Kurdistan University of Medical Sciences, Sanandaj, Iran.

\section{- Consent for publication}

Not applicable

\section{- Availability of data and materials}

The datasets used and analyzed during the current study are available from the corresponding author on reasonable request.

\section{- Competing interests}

The authors declare that they have no competing interests.

\section{- Funding}

This study was not funded.

\section{- Authors' contributions}

FZ(Fariam) was the major contributor in writing the manuscript, EM and FZ(Fatemeh) did the genetic tests, PCR test, and analysis; EG analyzed and interpreted the data; BM and FZ(Fariam) collected the data. All authors read and approved the final manuscript.

\section{- Acknowledgments}

Not applicable.

\section{References}

1. Bathia -RL. S. Epidemiology of leukemia in childhood Nathan and Oski's hematology of infancy and childhood (6th ed.) (2003), pp. 1081-1100. 
2. - Hunger SP, Mullighan CG. Acute Lymphoblastic Leukemia in Children. N Engl J Med. 2015;373(16):1541-52.

3. -Clarke RT, Van den Bruel A, Bankhead C, Mitchell CD, Phillips B, Thompson MJ.Clinical presentation of childhood leukaemia: a systematic review and meta-analysis. Arch Dis Child. 2016 Oct;101(10):894-901. doi: 10.1136/archdischild-2016-311251.

4. -Whitehead TP, Metayer C, Wiemels JL, Singer AW, Miller MD. Childhood Leukemia and Primary Prevention. Curr Probl Pediatr Adolesc Health Care. 2016 Oct;46(10):317-52. doi:10.1016/j.cppeds.2016.08.004.

5. -Belson M, Kingsley B, Holmes A. Risk factors for acute leukemia in children: a review. Environ Health Perspect. 2007 Jan;115(1):138-45.

6. -Carroll WL, Bhatla T. "Acute Lymphoblastic Leukemia. In: ed. Eds. Lanzkowsky P, Lipton JM, Fish JD. " in Lanzkowsky's Manual of Pediatric Hematology and Oncology. 6. London: Elsevier; 2016. pp. 367-89. doi:10.1016/B978-0-12-801368-7.00018-1.

7. -Bhojwani D, Howard SC, Pui CH. High-risk childhood acute lymphoblastic leukemia. Clin Lymphoma Myeloma. 2009;9(Suppl 3):222-30.

8. - WJ, Aston DE, Hope AK, Nowak BW, Robinson, et al. A systematic investigation of the maximum tolerated dose of cytotoxic chemotherapy with and without supportive care in mice.2017.

9. -Methotrexate Side. EffectsMedically reviewed by Drugs.com. Last updated on Feb 6, 2019.

10. -Ranjita Santra Soumeek Choudhury.Acute methotrexate ingestions in adults: A review on ever-rising consumption of methotrexate since 1980s.2015.

11. -Gutierrez-Í2Urena S, Molina JF, Garcia CO, Cuéllar ML, Espinoza LR. Pancytopenia secondary to MTX therapy in rheumatoid arthritis. Arthritis Rheum. 1996;39:272-6.

12. Sotoudehmanesh -R, Anvari B, Akhlaghi M, Shahraeeni S, Kolahdoozan S. Methotrexate Hepatotoxicity in Patients with Rheumatoid Arthritis.2010.

13. -Bethesda (MD). LiverTox: Clinical and Research Information on Drug-Induced Liver Injury [Internet]. National Institute of Diabetes and Digestive and Kidney Diseases; 2012-.Last Update: April 8, 2013.

14. -Gilani ST, Khan DA, Khan FA, Ahmed M. Adverse effects of low dose methotrexate in rheumatoid arthritis patients. J Coll Physicians Surg Pak. 2012;22:101-4.

15. Eivaz-Mohammadi -FernandoGonzalez-Ibarra,S, Surapaneni S, Alsaadi H, Syed AK. Simon Badin, Valentin Marian, and Mazhar Elamir..Methotrexate Induced Pancytopenia.Volume 2014, Article ID 679580, 4 pages.

16. -Urayama KY, Wiencke JK, Buffler PL, Wiemels JL. The role of MDR1 gene polymorphisms in the genetic susceptibility to childhood leukemia. Ann Epidemiol. 2002;12:497.

17. -Zhang H, Zhang Z, Li GABCB. 1 polymorphism and susceptibility to acute lymphoblastic leukemia: a meta analysis. Int J Clin Exp Med. 2015 May;15(5):7585-91. 8(. eCollection 2015.

18. -Malaysia K, Kerian. Kelantan, Malaysia ABCB1 genetic variants in leukemias: currentinsights into treatment outcomesRavindran AnkathilHuman Genome Centre, School ofMedical Sciences,2017. 
19. -Ambudkar SV, Kimchi-Sarfaty C, Sauna ZE, Gottesman MM. P-glycoprotein: from genomics to mechanism. Oncogene. 2003;22(47):7468-85.

20. -Ruth A, Stein WD, Rose E, Roninson IB. Coordinate changes in drug resistance and drug-induced conformational transitions in altered-function mutants of the multidrug transporter P-glycoprotein. Biochemistry. 2001;40:4332-9.

21. -Kimchi-Sarfaty C, Oh JM, Kim I-W, et al. A "Silent" polymorphism in the MDR1 gene changes substrate specificity. Science. 2007;315:525-8.

22. -Sauna ZE, Kimchi-Sarfaty C, Ambudkar SV, Gottesman MM. Silent polymorphisms speak: how they affect pharmacogenomics and the treatment of cancer. Cancer Res. 2007;67(20):9609-12.

23. -Cascorbi I, Gerloff T, Johne A, et al. Frequency of single nucleotide polymorphisms in the Pglycoprotein drug transporter MDR1 gene in white subjects. Clin Pharmacol Ther. 2001;69(3):16974.

24. -Salimizand H, Amini S, Abdi M, Ghaderi B, Azadi NA. Concurrent effects of ABCB1 C3435T, ABCG2 C421A, and XRCC1 Arg194Trp genetic polymorphisms with risk of cancer, clinical output, and response to treatment with imatinib mesylate in patients with chronic myeloid leukemia. Tumour Biol. 2016 Jan;37(1):791-8.

25. - Available on:https://www.snpedia.com/index.php/Rs1045642.

26. -Woodahl EL, Crouthamel MH, Bui T, Shen DD, Ho. RJ.MDR1 (ABCB1) G1199A (Ser400Asn) polymorphism alters transepithelial permeability and sensitivity to anticancer agents. Cancer Chemother Pharmacol. 2009 Jun;64(1):183-8. doi:10.1007/s00280-008-0906-4. Epub 2009 Jan 4.

27. -Zgheib NK, Akra-Ismail M, Aridi C, et al. Genetic polymorphisms in candidate genes predict increased toxicity with methotrexate therapy in Lebanese children with acute lymphoblastic leukemia. Pharmacogenet Genomics.

28. Gregers -J, Gréen H, Christensen IJ, Dalhoff K, Schroeder H, et al. Polymorphisms in the ABCB1 gene and effect on outcome and toxicity in childhood acute lymphoblastic leukemia. Pharmacogenomics J. 2015 Aug;15(4):372-9.

29. -Bergmann TK1, Brasch-Andersen C, Gréen H, Mirza MR, Skougaard K, Wihl J, Keldsen N, Damkier P, Peterson C, Vach W. Brøsen K.Impact of ABCB1 variants on neutrophil depression: a pharmacogenomic study of paclitaxel in 92 women with ovarian cancer. Basic Clin Pharmacol Toxicol. 2012 Feb;110(2):199-204.

30. -Yao S, Sucheston LE, Zhao H, Barlow WE, Zirpoli G, Liu S, et al.Germline genetic variants in ABCB1, $A B C C 1$ and $A L D H 1 A 1$, and risk of hematological and gastrointestinal toxicities in a SWOG Phase III trial S0221 for breast cancer. Pharmacogenomics J. 2014 Jun;14(3):241-7. doi: 10.1038/tpj.2013.32. Epub 2013 Sep 3.

31. -Samara SA, Irshaid YM, Mustafa KN. Association of MDR1 C3435T and RFC1 G80A polymorphisms with methotrexate toxicity and response in Jordanian rheumatoid arthritis patients. Int $\mathrm{J}$ Clin Pharmacol Ther. 2014 Sep;52(9):746-55. doi:10.5414/CP202098. 
32. Suthandiram -Sujatha, Gan G-G. Shamsul Mohd Zain,Ping-Chong Bee, Lian L-H, Chang K-M et alEffect of polymorphisms within methotrexate pathway genes on methotrexate toxicity and plasma levels in adults with hematological malignancies.PHARMACOGENOMICSVOL. 15, NO. 11.

33. -Troels K, Bergmann H, Gréen C, Brasch-Andersen MR, Mirza, Jørn H, et al. Retrospective study of the impact of pharmacogenetic variants on paclitaxel toxicity and survival in patients with ovarian cancer. European Journal of Clinical Pharmacology, Springer Verlag, 2011, 67 (7), pp. 693-700. ff10.1007/s00228-011-1007-6ff. f.

\section{Tables}

Table 1: Demographic table

\begin{tabular}{|c|c|c|c|}
\hline - & & $\underline{\mathbf{N}}$ & $\underline{\%}$ \\
\hline \multirow[t]{2}{*}{ Gender } & female & 36 & 44.6 \\
\hline & male & 45 & 55.5 \\
\hline \multirow[t]{4}{*}{ Type of ALL } & Pre B cell & 75 & 92.59 \\
\hline & T Cell & 4 & 4.93 \\
\hline & Pre $B$ cell+AML & 2 & 2.49 \\
\hline & Early Pre B cell & 0 & 0 \\
\hline \multirow{2}{*}{ At-risk groups } & Standard / low risk & 62 & 76.54 \\
\hline & Medium / high risk & 19 & 23.45 \\
\hline
\end{tabular}

Table 2: prevalence of normal and mutant alleles of the ABAB1 gene at the same point 


\begin{tabular}{|llll|}
\hline$\underline{\text { Allele }}$ & & $\underline{\mathbf{N}}$ & $\underline{\%}$ \\
$\underline{1199}$ & $\underline{\mathrm{AA}}$ & $\underline{1}$ & $\underline{1.2}$ \\
& $\underline{\mathrm{GA}}$ & $\underline{3}$ & $\underline{3.7}$ \\
& $\underline{\mathrm{GG}}$ & $\underline{77}$ & $\underline{95.1}$ \\
$\underline{\mathbf{3 4 3 5}}$ & $\underline{\mathrm{CC}}$ & $\underline{24}$ & $\underline{29.4}$ \\
& $\underline{\mathrm{CT}}$ & $\underline{31}$ & $\underline{38.3}$ \\
& $\underline{\mathrm{TT}}$ & $\underline{26}$ & $\underline{32.1}$ \\
\hline
\end{tabular}

Table 3: Relationship between drug side effects in ALL patients with ABAB1 gene mutation at point 1199

\begin{tabular}{|lllll|}
\hline Drug side effects & Mutation of the ABAB1 gene at point 1199 & P-Value \\
\hline Gastrointestinal toxicity & 18 & mutated & normal & \\
\hline leukopenia & 66 & 4 & 19 & 1.000 \\
\hline anemia & 52 & 2 & 70 & 1.000 \\
\hline Thrombocytopenia & 54 & 3 & 54 & 0.597 \\
\hline Neutropenia & 71 & 3 & 57 & 1.000 \\
\hline Liver toxicity & 43 & 3 & 74 & 0.308 \\
\hline Renal toxicity & 1 & 0 & 46 & 0.630 \\
\hline
\end{tabular}

Table 4: Relationship between drug side effects in ALL patients with ABAB1 gene mutation at point 3435 


\begin{tabular}{|lllll|}
\hline Drug side effects & \multicolumn{3}{c}{ Mutation of the ABAB1 gene at point 3435 } & P-Value \\
\hline normal & mutated & normal & \\
\hline Gastrointestinal toxicity & 7 & 12 & 19 & 0.619 \\
\hline anemia & 20 & 50 & 70 & 0.724 \\
\hline Thrombocytopenia & 19 & 35 & 54 & 0.121 \\
\hline Neutropenia & 20 & 37 & 57 & 0.116 \\
\hline Liver toxicity & 22 & 52 & 74 & 1.000 \\
\hline Renal toxicity & 13 & 33 & 46 & 0.096 \\
\hline
\end{tabular}

\section{Figures}




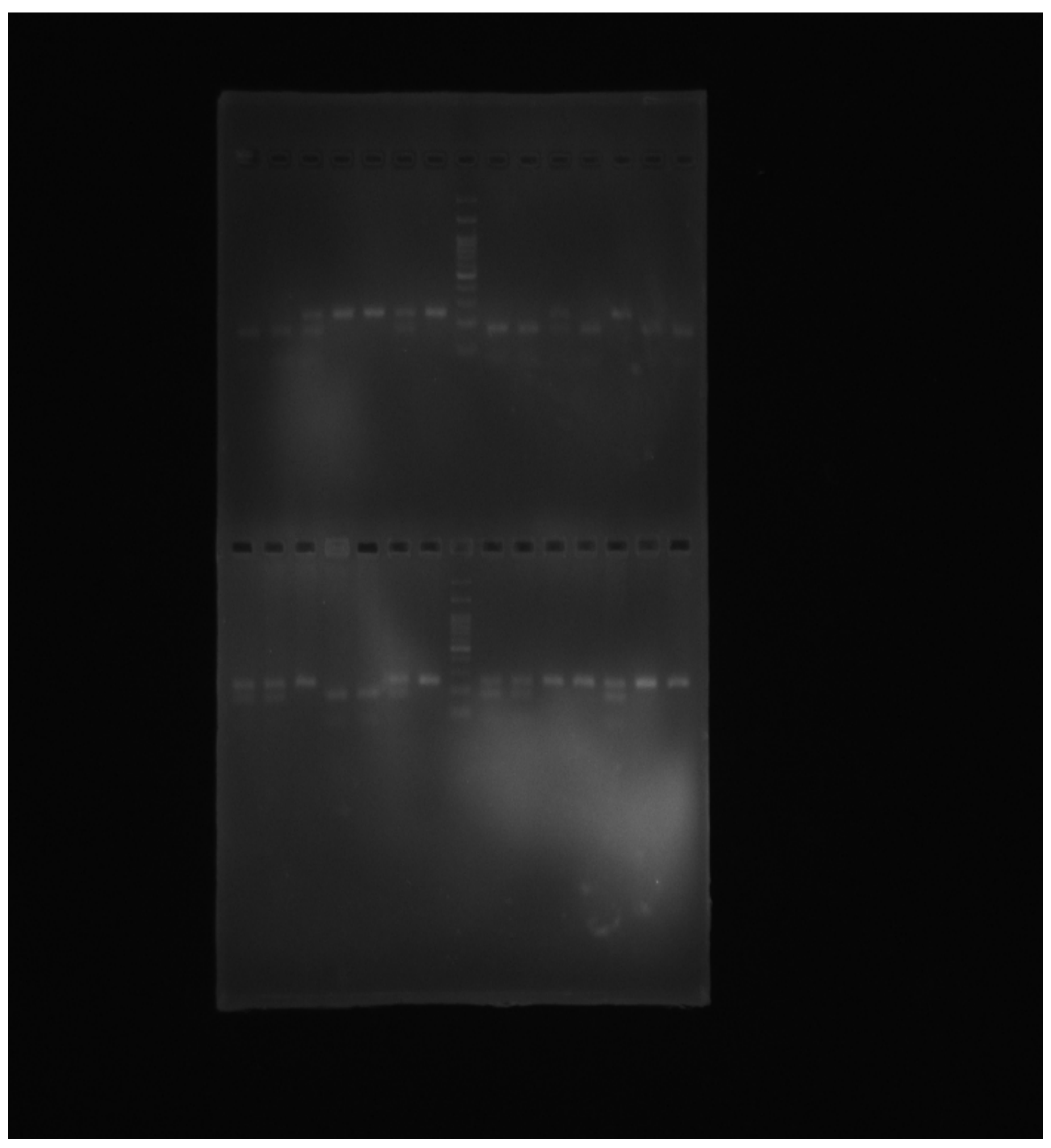

Figure 1

The final agarose gel of the ABCB1 product of gene PCR product at point 3435 


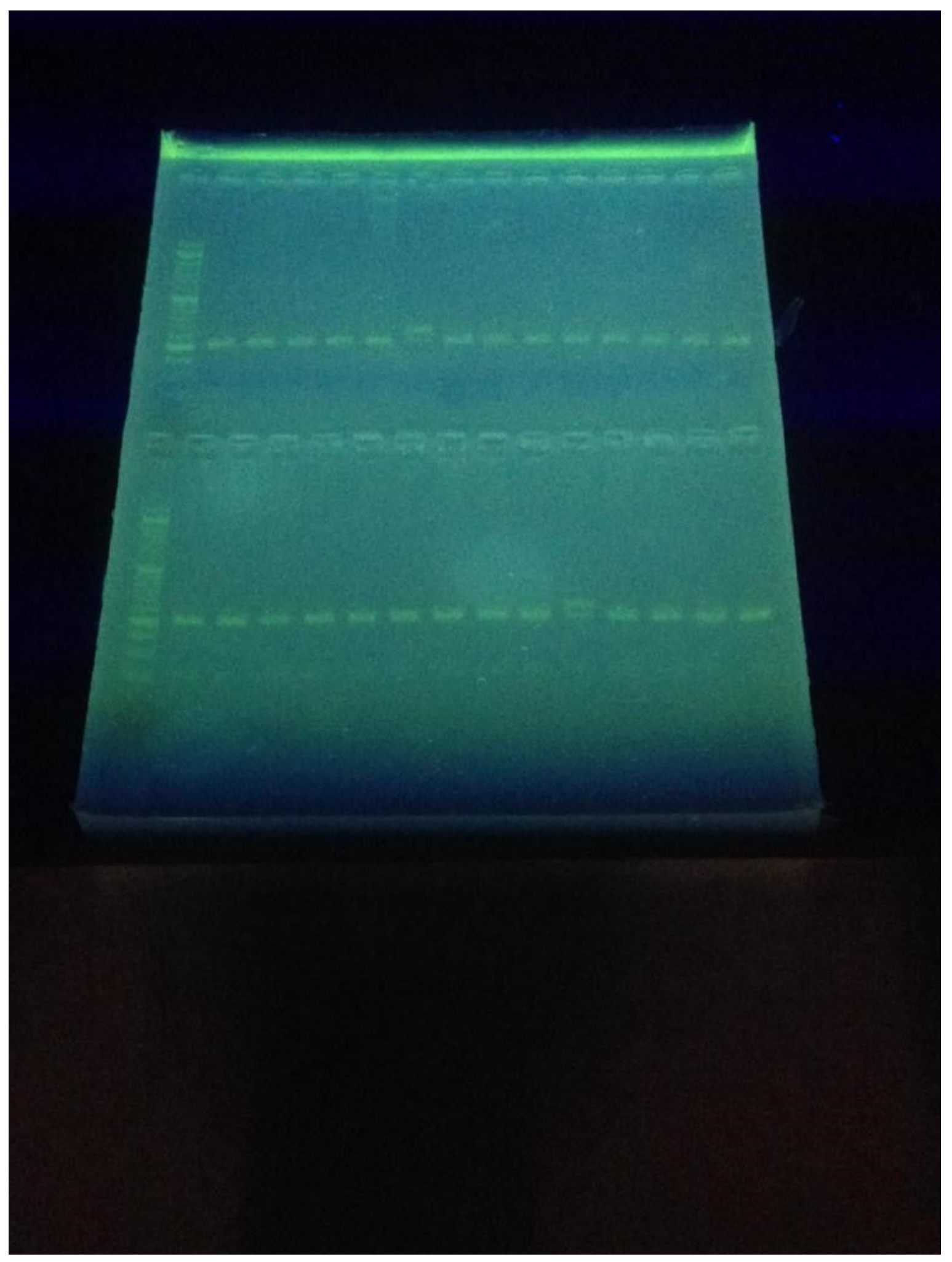

Figure 2

The final agarose gel of the ABCB1 gene at point 1199

\section{Supplementary Files}

This is a list of supplementary files associated with this preprint. Click to download. 
- STROBEchecklistv4combinedPlosMedicine1.docx 